Gold Medal for Exceptional Service in recognition of his "outstanding scientific administration, research accomplishments in the field of scintillation spectrometry, high-energy bremsstrahlung spectra and attenuation of high energy radiation".

Silver Medals have been awarded by the U.S. Department of Commerce to the following members of the National Bureau of Standards: R. F. Ackermann, for his work in connexion with the development of high-precision techniques and equipment used for calibration of line standards of unusual length; W. W. Brown, for his part in the establishment of long-wave standard frequency broadcast stations including station $W W V L$ at Sunset, Colorado; Dr. L. V. Spencer and C. M. Eisenhauer, who received a joint award for outstanding contributions to civil defence, through the development of radiation shielding engineering; Dr. D. Goodwin, for his work on measurements of the thermodynamic properties of fluid hydrogen; H. W. Lance, for outstanding performance in improvement of electronic standards, measurements and calibrations; C. E. Haven, for his contributions to dimensional metrology and standardization; G. Hefley, for his work in innovating and developing the "Loran- $C$ Clock"; M. R. Meyerson, for his contributions to the field of physical metallurgy, particularly with reference to the development of gauge block steel; A. Mijares, for his contribution to the Bureau's technical programme over a long period of time; Dr. R. S. Roth, for contributions to the knowledge of inorganic phase relations in the field of non-metallic mineral products and for active and meritorious authorship; Dr. A. H. Scott, for his services in the field of precision measurements of the dielectric properties of matter; F. Sera, for his achievements in operation and improvement of the continuous broadcast of technical radio services; Dr. M. C. Thompson, for his part in the conducted research on the physics of the troposphere; Dr. W. L. Wiese, for outstanding research in the field of plasma physics.

\section{Britain and the European Markets}

UNDER the title Producing for European Markets, the text of five papers given at the Joint British Productivity Council-Export Council for Europe conference at the 1961 Factory Equipment Exhibition in London has now been published by the British Productivity Council (Pp. 40. London: British Productivity Council, 1962. 2s. 6d.). Mr. Bertil Neuman, a marketing consultant of Stockholm, discussing Europe's consumer goods requirements, makes some criticism of British business men, more particularly of lack of sales policy and attention to details of consumers' requirements, and urges the need to look well ahead. Mr. J. Hanning, managing director of a Paris firm, dealing with Europe's capital goods requirements, also insists on the importance of marketing capital goods which represent some technical advance, but his paper is noteworthy for constructive suggestions about the qualifications of agents, specifications, the importance of punctuality and of avoiding the use of abbreviations and ambiguities, etc. The Hon. Brian Rootes, dealing with the way Britain can face the challenge of Europe, is confident that Britain has the technical capacity, but stresses the need for rationalization of products, standardization including the adoption of the metric system of weights and measures, attention to safety and like requirements, and the framing of common policies in testing methods and like matters. The remaining two papers, by Mr. A. S. Booth and Mr.
O. F. Reichwald, present case studies of experience with consumer goods and with capital goods, respectively. The former lays stress on packaging, the utilization of spare capacity, increasing the efficiency of production, and the guaranteeing of quality and delivery, while the latter emphasizes the vital importance of attention to detail and of prompt servicing.

\section{Royal Dutch Shell Group : Chemical Enzymology Unit}

A Chemical Enzymology Unit, with a new labor. atory near Sittingbourne in Kent, is being set up by the Royal Dutch/Shell Group. Jointly in charge of this Unit will be Dr. J. W. Cornforth, for some years a member of the National Institute of Medical Research, and Dr. G. J. Popják, at present director of the Medical Research Council's Experimental Radiopathology Research Unit. They will be assisted by Dr. Rita Cornforth, wife of Dr. John Cornforth. The Unit's work will embrace both basic research and research on topics of shortcr-range interestmainly, but not exclusively, in the sphere of 'biological chemistry', on which science Shell relies very largely in its development of pesticides and herbicides.

The search for new chemicals and their testing for this purpose is already carried out at Woodstock Agricultural Research Centre, near Sittingbourne. Close to it is the Tunstall Toxicology Laboratory. The new Enzymological Laboratory brings into this same area a third focal point-that for basic chemical studies in relation to life processes.

Dr. Popják will join the Unit on October 1 and Dr. and Mrs. Cornforth on November 1. Their laboratory is expected to be completed on April 1, 1963. In addition to the permanent staff, a limited number of scientists working in kindred fields in the universities will be welcome there for periods of research up to about three years in duration.

\section{Register of Research in the Human Sciences, 1960-61}

UNDER the heading Register of Research in the Human Sciences, 1960-61, the Warren Spring Laboratory of the Department of Scientific and Industrial Research has issued a most useful compendium concerning research bodies within the United Kingdom dealing with the human sciences (Pp. xi +44 (11 plates). London: H.M.S.O., 1962. 10s. net). Included within this title of 'human sciences' aro such subjects as anatomy, cultural anthropology, indus. trial relations, management, medical sociology, physiological psychology, physiology, political science, psychology, social disorganization (criminology), social economics, economic history, social psychology, sociology and demography, and various marginal entries. The major section details the various fields of research, giving the address, telephone number and director of the research institutes, councils, laboratories, etc., concerned. Under these are listed the projects which have been or are being undertaken, including a brief description, the name of the person (or research committee) responsible for the research, research workers, approximate dates of starting and completion of interim and final reports, bodies concerned with the inquiry, etc. An index of institutes and their entries, dealing with universities, technical colleges, other institutes and private research workers, is supplied, and also a subject-index. The register is a most useful publication and an essential reference work to those who have to, or wish to, keep track of research in the human sciences, to those who wish to 